\title{
ENSINO REMOTO: APRESENTAÇÃO DE JOGOS DA PLATAFORMA WORDWALL PARA ENSINAR ESTATÍSTICA NOS ANOS INICIAIS
}

\section{ARTIGO ORIGINAL}

JESUS, Rafaela Rodrigues de ${ }^{1}$, MOTA, Vania Corrêa ${ }^{2}$

JESUS, Rafaela Rodrigues de. MOTA, Vania Corrêa. Ensino remoto: Apresentação de jogos da plataforma Wordwall para ensinar estatística nos anos iniciais. Revista Científica Multidisciplinar Núcleo do Conhecimento. Ano. 06, Ed. 12, Vol. 04, pp. 102-122. Dezembro de 2021. ISSN: 2448-0959, Link de acesso: https://www.nucleodoconhecimento.com.br/educacao/apresentacao-dejogos

\section{RESUMO}

Levando em consideração o momento pandêmico do Covid-19 e da aplicação do ensino remoto, as plataformas digitais aparecem como ferramentas facilitadoras do ensino. A utilização de jogos didáticos digitais é uma alternativa para o ensino online, por ser prático e de fácil acesso, cria-se a oportunidade para os alunos observarem e manipularem os conteúdos. O artigo tem como objetivo apresentar a utilização de jogos didáticos digitais a partir da ferramenta online gratuita Wordwall, tendo como problemática identificar como os professores desenvolvem e trabalham com o ensino da Estatística no componente curricular de Matemática para os anos iniciais do Ensino Fundamental. Para coleta de dados o método utilizado foi a aplicação de um questionário, direcionado aos seis docentes que lecionam a disciplina de Matemática do Ensino Fundamental Séries Iniciais da Escola Estadual São Francisco, localizada no município de Ji-Paraná/RO. As questões elaboradas tinham como foco de investigação, verificar se os docentes faziam uso de tecnologia e modelagem de jogos

\footnotetext{
${ }^{1}$ Pós-Graduanda em Educação Matemática, Licenciatura em Matemática.

2 Orientadora. Doutorado em Engenharia Agrícola, Mestrado em Estatística e Experimentação, Bacharelado em Ciências Contábeis, Licenciatura em Matemática.
} 
digitais com ferramentas gratuitas no período de pandemia e perceber as dificuldades em ensinar Estatística e Probabilidade nas Séries Iniciais, observando a posição do professor na utilização desses recursos. Com o intuito de facilitar a assimilação dos conteúdos de Probabilidade e Estatística, recomendou-se a utilização de jogos educativos digitais da plataforma Wordwall como complemento ao processo de ensino e aprendizagem. Realizou-se a edição de dois modelos de jogos digitais, no intuito de analisar cenários de aleatoriedade e identificar a probabilidade de um evento acontecer nas situações apresentadas e mostradas nos games. Observou-se que os professores possuem alguma dificuldade em trabalhar com ferramentas tecnológicas, e em ministrar conteúdos de Estatística e Probabilidade nas séries iniciais do Ensino Fundamental. Concluiu-se que a apresentação da plataforma online gratuita Wordwall foi de extrema relevância para os professores que trabalham com o ensino da Estatística no componente curricular de Matemática para os anos iniciais do Ensino Fundamental da Escola Estadual São Francisco. Os docentes compreenderam que a utilização desta ferramenta pode ser uma aliada, no processo de ensino e aprendizagem de Probabilidade e Estatística, mesmo que seja necessário realizar formações pedagógicas.

Palavras-chave: Estatística, Jogos Digitais, Wordwall, Probabilidade, Ensino Remoto.

\section{INTRODUÇÃO}

Desde o reconhecimento do status de pandemia pela Organização Mundial da Saúde (OMS, 2020) e decretado o estado de emergência nacional, em virtude da pandemia do novo Corona Vírus, uma das primeiras medidas tomadas pelo governo foi a suspensão das aulas presenciais em todos os níveis de ensino (BRASIL, 2020). Com as mudanças decorrentes da pandemia, associadas às medidas de distanciamento social recomendadas pelos órgãos de saúde nacional e internacional, iniciou-se um grande impacto em toda a sociedade, sendo que milhares de alunos tiveram suas atividades escolares presenciais suspensas e substituídas por ensino remoto. (GROSSI; MINODA e FONSECA, 2020). 
Levando em consideração o momento pandêmico e de aplicação do ensino remoto, as plataformas digitais aparecem como ferramentas facilitadoras do ensino. A utilização de jogos didáticos digitais é uma alternativa para o ensino online, por ser prático e de fácil acesso, cria-se a oportunidade para os alunos observarem e manipularem os conteúdos, e aprender brincando. Os jogos fazem com que os alunos construam seu conhecimento, despertando o interesse e a curiosidade (FRANCO et al., 2018), se tornando ativo do processo de aprendizagem dos conteúdos matemáticos.

A Educação Matemática está presente em todos os lugares, faz parte do nosso cotidiano, como em supermercados, postos de gasolina, bancos, nos sinais de trânsitos, entre outros, uma vez que, em cada um desses espaços citados à Matemática é inserida desempenhando diferentes funções, que vai de um simples cálculo de somatório ou algo mais complexo envolvendo as funções geométricas, os sistemas de medidas, jogos envolvendo a probabilidade e a própria estatística.

De acordo com Santana (2021) é importante salientar o objetivo da utilização de jogos no processo de ensino aprendizagem, como facilitador, é necessário planejamento adequado e regras bem definidas. Porém os jogos por si só não são ferramentas transformadoras do ensino da Matemática e da Estatística, mas são recursos didáticos capazes de dinamizar e facilitar o ensino. Diante do exposto, este artigo tem como objetivo, apresentar a utilização de jogos didáticos digitais a partir da ferramenta online gratuita Wordwall, tendo como problemática identificar como os professores desenvolvem e trabalham com o ensino da Estatística no componente curricular de Matemática para os anos iniciais do Ensino Fundamental.

\section{REFERENCIAL TEÓRICO}

\subsection{JOGOS DIDÁTICOS E SUA IMPORTÂNCIA PARA O APRENDIZADO DE ESTATÍSTICA}

O ensino está passando por grandes transformações nas metodologias aplicadas em sala de aula, o que reflete em mudanças dentro das estruturas escolares e nos 
métodos de ensino. Diante a estas mudanças, o processo de ensino necessita de transformações e inovações nos métodos de ensinar. As escolas, há algum tempo buscam por novas metodologias para trabalhar o ensino da Estatística, de forma que este ensino pudesse beneficiar os alunos e professores, tanto na vida profissional quanto na resolução de problemas do seu cotidiano. Para a aprendizagem da Estatística durante as aulas de Matemática, os jogos e as atividades lúdicas são capazes de proporcionar um trabalho significativo, pois fazem parte de uma ideia construtivista, onde o aluno é o centro do processo de aprendizagem, conforme afirma Lima (2020).

\begin{abstract}
O brincar é uma atividade prática, por meio dela os sujeitos constroem e transformam seu mundo, ressignificando assim a sua realidade. $O$ brincar compreende a produção de um mundo particular do indivíduo, que por sua vez transforma o lugar e o tempo em que ele pode acontecer. Quando a criança brinca, ela se depara com situações diversas, tais como desafios e problemas, havendo assim a necessidade constante de busca de soluções as situações colocadas. Deste modo, o brincar é mais que uma atividade lúdica pois possui especificidades voltadas para a obtenção de informação, contribui para que a criança adquira flexibilidade, desperta o interesse e a vontade de experimentar novos caminhos, proporciona momentos de interação em diversos contextos, incentiva a autoconfiança bem como eleva a autoestima, estimulando a criança a persistir e perseverar (SANTOS, 2011, p. 9).
\end{abstract}

O ato de brincar é uma característica inerente do ser humano, que não está voltada somente para a criança, por isso adultos também brincam, em especial aqueles que possuem conhecimentos dos benefícios trazidos por esta atividade fantástica, mas que tem se tornado estranha em nossas vidas (SOUSA, 2016).

Ainda segundo Sousa (2016), nota-se que atualmente as brincadeiras foram eliminadas ou substituídas por outras consideradas produtivas, devido a muitos fatores, dentre os quais podemos citar a redução de espaço geográfico com o crescimento das cidades, as mudanças nos hábitos de vida da população com advento da tecnologia, o uso de mídias sociais, jogos digitais, aplicativos de filmes, música, entre outros, ou até mesmo à falta de conhecimento sobre o assunto.

No entanto, para que o excesso de tecnologia não venha afetar o desenvolvimento da criança, é imprescindível, abordá-la como um meio facilitador na questão do ensino, 
porque os professores podem utilizá-la para pesquisas, fontes ilustrativas, vídeos educativos etc. (SILVA e SILVA, 2017). Como exemplo, podemos citar o uso de jogos digitais (LEMOS, 2016), que no ensino fundamental nas séries inicias, possibilita ao aluno uma compreensão mais ampla do assunto tratado em sala de aula, entretendo, na maioria das vezes esse recurso deixa de ser usado pelos docentes, por acharem que o uso de tecnologia educacional dentro da sala de aula seja um desafio inalcançável para o ensino público e com isso não a considera uma opção dentro do planejamento, sendo que podem encontrar uma infinidade de possibilidades de ferramentas gratuitas.

É indubitável o avanço da tecnologia, entretanto, existe uma grande demora para serem utilizadas nas escolas, porém, é visível a sua importância na introdução aos recursos metodológicos ligados ao ensino digital nas aulas, sendo os jogos e as brincadeiras ótimas opções utilizadas por professores para melhorar o aprendizado das crianças em relação a capacidade de sintetizar as informações, fazer a leitura e interpretação de dados apresentados em tabelas e gráficos.

De acordo com Sousa (2016) na idade Média os jogos serviam para divulgar princípio de moral ética e já se tinha a ideia de usá-lo junto aos conteúdos de disciplinas escolares, porém, não era considerado sério, por estar associado também ao azar. Em contrapartida, no renascimento, havia uma compulsão lúdica. Os jogos eram aceitos como uma conduta livre, que favorecia a ampliação da inteligência e facilitava o estudo, sendo adotado como ferramenta de aprendizagem de conteúdos escolares.

Percebe-se que os jogos e brincadeiras fazem parte da humanidade desde há muitos séculos, adaptando-os para a realidade escolar nota-se um significativo progresso. Visto que facilita o aprendizado dos alunos, já que favorece a construção do conhecimento científico e a imaginação, instigando-os a buscar soluções para situações propostas durante os jogos, estimula o raciocínio, e eleva o nível de pensamento estatístico, pois encoraja-os a refletir sobre os processos, criticar seu próprio trabalho, perceber as limitações dos conteúdos e assim observar as diferentes dimensões da teoria e da prática (CAMPOS; WODEWOTZKI; JACOBINI, 2011). 
Já Muniz (2010), diz que o valor dos jogos para a aprendizagem ganha força e importância a partir dos teóricos construtivistas, especialmente a partir da ideia de que o jogo potencializa a zona de desenvolvimento proximal (ZDP), conforme é afirmada na Teoria Vigotskiana (1991).

A zona desenvolvimento proximal provê psicólogos e educadores de um instrumento através do qual se pode entender o curso interno do desenvolvimento. Usando esse método podemos dar conta não somente dos ciclos e processos de maturação que já foram completados, como também daqueles processos que estão em estado de formação, ou seja, que estão apenas começando a amadurecer e se desenvolver (VYGOTSKY, 1991, p. 58).

Vygotsky (1991) defende que a ZDP é essencial para o aprendizado dos alunos, já que a criança se relaciona com os outros, aprendendo a coletividade nas atividades. Dessa forma, por meio de um jogo ou brincadeira em grupo, torna-se um mecanismo fundamental de ensino-aprendizagem.

Nos Parâmetros Curriculares Nacionais de 1998 define que, os jogos constituem uma forma interessante de propor problemas, pois permitem que estes sejam apresentados de modo atrativos e favoreçam a criatividade na elaboração de estratégias de resolução e buscas de soluções. (BRASIL, 1998). Em relação ao aprendizado e ensino de Estatística os Parâmetros Curriculares Nacionais - PCN's, denomina-se esse eixo como Tratamento de Informação, que vem ganhando espaço no Ensino Fundamental e recebendo um cuidado especial (GONÇALVES e STRAPASSON, 2007).

Cabe a cada educador saber utilizar essa ferramenta como recurso didático, pois ele deve despertar o interesse das crianças, com a sua participação. $O$ educador deve estar preparado com recursos metodológicos adequados para cada situação problema que escolha e decida desenvolver em sala de aula.

\subsection{CONSTRUÇÃO DE MATERIAIS DIDÁTICOS NA ESTATÍSTICA}

O professor sempre está em busca de inovações que facilite o aprendizado dos alunos. Logo, a utilização de materiais didáticos como recursos de ensino, são 
ferramentas indispensáveis, visto que os alunos aprendem muito mais quando visualizam e manipulam. Alguns estudos ressaltam a importância de materiais didáticos para o desenvolvimento cognitivo dos alunos.

Os documentos oficiais, que regem a Educação Básica brasileira, visam que as aulas de Matemática devem apresentar ferramentas extras para auxiliar na aprendizagem dos alunos. Tanto os PCN, como a nova Base Nacional Comum Curricular (BNCC) recomendam que os professores façam uso de materiais didáticos para efetivar a construção de conceitos e auxiliar no desenvolvimento cognitivo dos alunos (PEREIRA; DIAS; JUNIOR, 2018, p. 1010).

A utilização de materiais didáticos proporciona a ideia do apoio visual ou do visual-tátil como facilitador para a aprendizagem, e não é algo recente, já vem sendo estudado há muitos anos. O método de aprender brincando é importante para incentivar não só a imaginação das crianças durante o seu desenvolvimento, sendo também capaz de contribuir no processo de desenvolvimento de competências cognitivas e socioemocionais.

Pois em uma pesquisa aplicada com professores, com relação às vantagens da utilização destes materiais, obteve-se que a utilização do material didático em sala de aula oportunizava a visualização do assunto; facilitava a aprendizagem, (já que o aluno aprendia fazendo), melhorava o entendimento do conteúdo e aumentava interesse e motivação (MARSHALL; PAUL, 2008).

Comprovando a importância dos recursos didáticos em alguns estudos, podemos ir um pouco além, com um estudo sobre materiais didáticos com tema de estatística, visto que os materiais didáticos podem ser classificados como materiais físicos (manipuláveis e estatísticos) e recursos tecnológicos (virtuais, softwares, planilhas eletrônicas dentre outros). Segundo Mota et al. (2013) basta abrir uma página da internet para se deparar com gráficos estatísticos, que muitas das vezes não são apresentadas de forma didática, necessitando de promover o conhecimento de estatística à educação escolar desde os anos iniciais. Este artigo irá levar em consideração os materiais tecnológicos, já que alguns podem ser utilizados de forma gratuita, usando apenas internet, computador, celular ou tablet. Assim a proposta de ensino de Estatística pode tornar-se mais relevante com a utilização desses recursos, para a compreensão dos alunos, já no Ensino Fundamental Séries Iniciais. 
De acordo com Campos e Santana (2010), as contribuições à prática pedagógica do professor do Ensino Fundamental, em especial dos anos iniciais, que são os responsáveis pela alfabetização estatística, tem como objetivo apresentar sequências didáticas a partir de jogos que permitirão ao professor adotar uma postura educativa com ênfase na investigação do saber probabilístico e estatístico, em que se aprende estatística e probabilidade.

As autoras acima citadas, verificaram com a sequência didática "Jogo de palitos e a probabilidade", apresentado no formato de minicurso no X Encontro Nacional de Educação Matemática realizado em Salvador - BA, que teve como objetivo resolver situações-problema simples, que os participantes da atividade conseguiram identificar sucessos possíveis e seguros, por meio de questões baseadas no jogo, e, portanto, as questões que foram utilizadas e experimentadas pelos participantes serviram para avaliar chances e/ou probabilidades. Acrescentam, ainda, que já nas séries iniciais é possível conduzir a criança a coletar, representar e interpretar dados (CAMPOS e SANTANA, 2010).

Vale ressaltar que ao utilizar, por exemplo, o jogo de palitos que é muito explorado e jogado em uma determinada região, cabe ao professor usar a criatividade e adaptar os jogos de acordo com a realidade da sua região e a realidade dos alunos, fazendo sempre uma análise de cada conhecimento trazido do cotidiano dos seus alunos.

\subsection{PLATAFORMA WORDWALL}

A plataforma digital Wordwall possui como objetivo a criação de atividades e jogos interativos digitais, de acesso público ou privado. Foi desenvolvido com o intuito de criar atividades lúdicas personalizadas gamificadas. A ferramenta possui interface versátil com um leque de atividades que podem ser elaboradas utilizando diferentes recursos de uma só vez. Na figura 01 é possível ver a tela inicial da plataforma, onde são criados os jogos e diferentes tipos de atividade. 
Figura 1: Tela inicial da plataforma Wordwall.

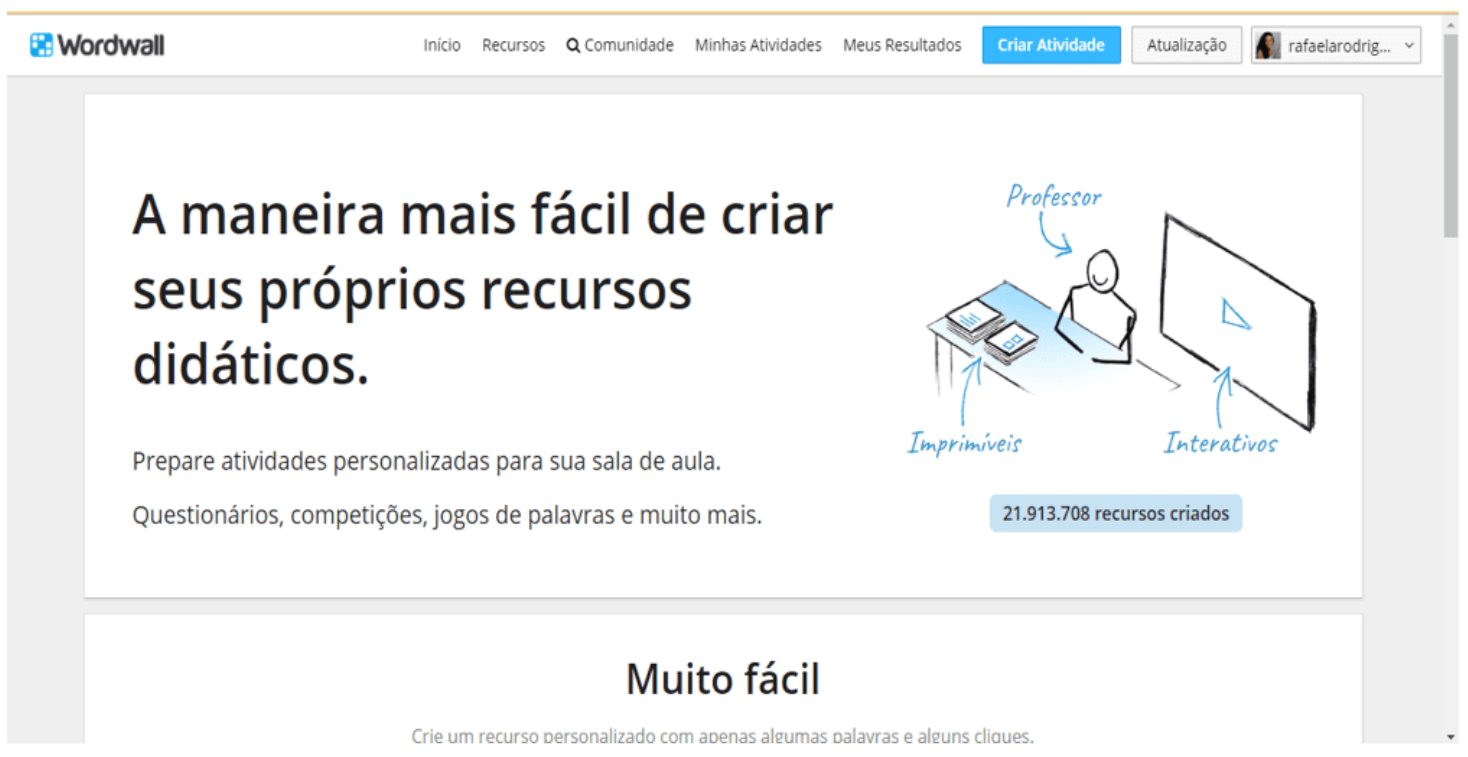

Fonte: Wordwall (2021).

$\mathrm{Na}$ tela inicial da plataforma, aparecem os seguintes ícones, início, recursos, comunidade, minhas atividades, meus resultados, criar atividade, atualização e o perfil do usuário cadastrado.

Para criar a atividade basta clicar em criar atividade e escolher uma atividade.

O sistema de criação e customização de atividades interativas, Wordwall, possui um vasto portfólio de atividades e minijogos que podem ser utilizados pelos docentes para trabalhar revisões, conceitos e avaliações, entre algumas outras finalidades. A ferramenta foi desenvolvida com o intuito de imergir as metodologias ativas com atividades digitais interativas ou para gerar listas de exercícios para imprimir e utilizar em sala de aula. O sistema digital de aprendizagem Wordwall pode ser utilizado de dois modos distintos: o gratuito possibilita a elaboração de até cinco atividades diferentes, que o docente pode realizar a edição posteriormente, caso queira criar novas tarefas sem custo, e o modo pago em que o usuário consegue utilizar livremente todos os recursos do sistema (WORDWALL, 2021). 
As atividades digitais elaboradas na ferramenta Wordwall podem ser jogadas de forma individual ou em grupo e em dispositivos eletrônicos, como em computador, tablet, smartphone, lousa interativa, desde que haja conexão com a internet.

\section{METODOLOGIA}

A pesquisa foi realizada na Escola Estadual São Francisco, nas series iniciais do Ensino Fundamental ( $1^{\circ}$ ao $5^{\circ}$ ano), localizada no município de Ji-Paraná/RO, o segundo maior no Estado de Rondônia. Com uma população estimada em 2017 de 132.667 habitantes, é o segundo mais populoso do estado e o décimo sexto mais populoso da Região Norte do Brasil (IBGE, 2021).

Foi aplicando no dia 17 de agosto de 2021, um questionário físico aos seis professores que lecionam a disciplina de Matemática do $1^{\circ}$ ao $5^{\circ}$ ano. O questionário foi elaborado com perguntas fechadas com intuito de diagnosticar quais as principais dificuldades encontradas pelos docentes em trabalhar com o ensino da Estatística e Probabilidade no componente curricular de Matemática nos anos iniciais do Ensino Fundamental. $\mathrm{Na}$ oportunidade foi apresentado aos professores a ferramenta digital Wordwall, com o intuito de levar a prática da elaboração e construção de materiais didáticos para o ensino e aprendizagem da Estatística nos anos iniciais do Ensino Fundamental. Os resultados da pesquisa foram tabulados no aplicativo da Microsoft Office Excel, e organizados a fim de determinar as dificuldades no ensino de Estatística e Probabilidades, bem como a aceitação na utilização de ferramentas digitais como apoio pedagógico.

Utilizou-se a ferramenta de criação de jogos e atividades digitais Wordwall, disponível através do endereço eletrônico: https://wordwall.net/pt. Para iniciar o processo de desenvolvimento do jogo online, não foi necessário conhecimento de código ou design de jogo, todos os 18 modelos de atividades estavam disponíveis na plataforma de maneira gratuita conforme evidenciado na figura 2.

Para o desenvolvimento do jogo virtual empregou-se habilidades da área de matemática da Base Nacional Comum Curricular (BNCC), sendo selecionados 2 
conteúdos. A primeira habilidade selecionada para o jogo 1 foi a (EF02MA21) para classificar resultados de eventos cotidianos aleatórios. Na segunda habilidade, no jogo 2 (EF04MA26) o aluno deverá ter a capacidade de determinar, entre eventos aleatórios cotidianos, os que possuem maior chance de ocorrência, levando em consideração o reconhecimento das características de resultados mais prováveis, sem a utilização de frações.

Figura 2: Tela de criação de atividades virtuais interativas.

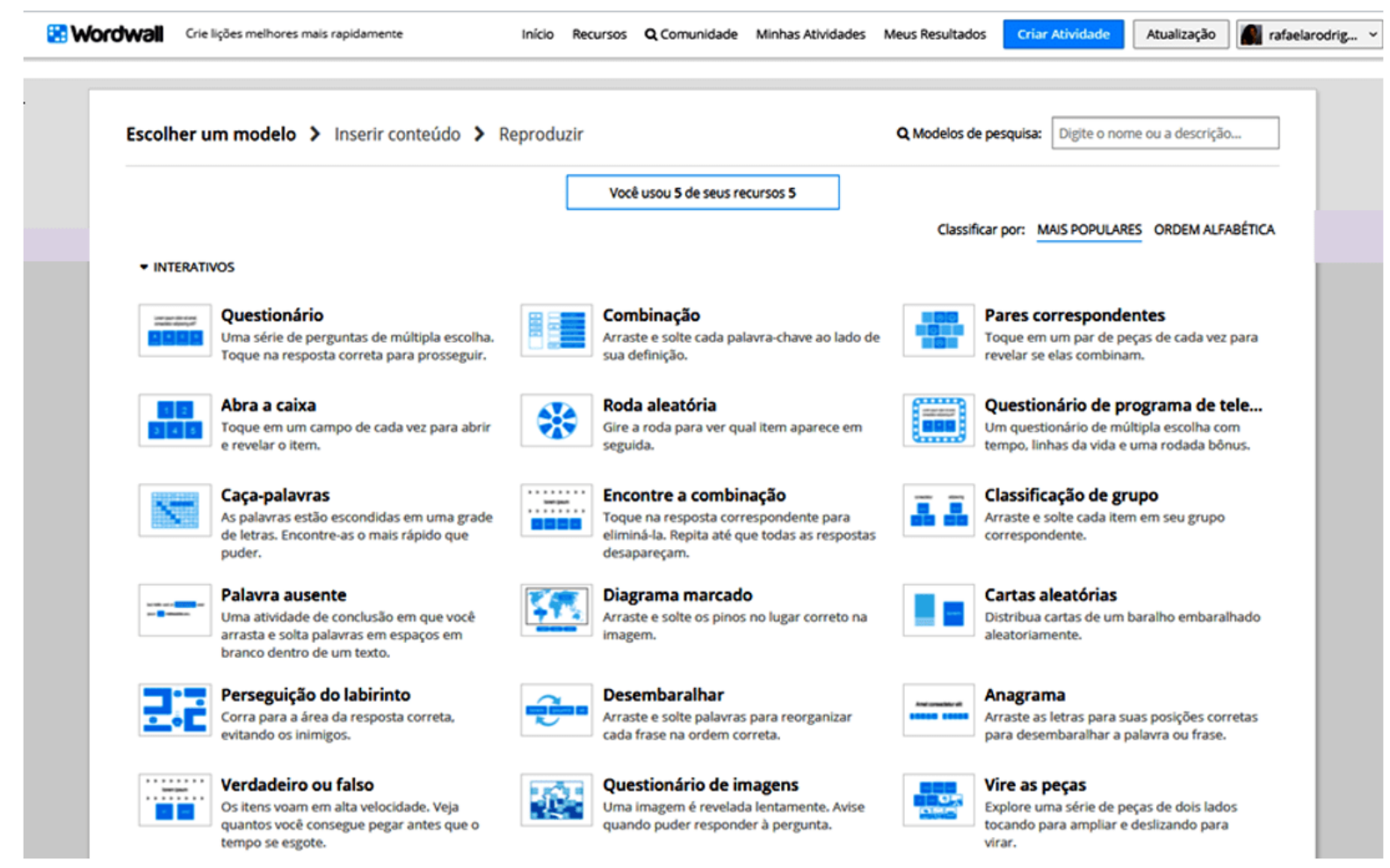

Fonte: https://wordwall.net/pt/create/picktemplate, (2021).

\section{RESULTADOS E DISCUSSÕES}

\subsection{MODELOS DE JOGOS DIGITAIS APRESENTADOS NA PESQUISA}

Realizou-se a edição de 2 modelos de jogos digitais, sendo estes disponíveis para acesso remoto através dos links: jogo 1: https://wordwall.net/play/21400/340/729 e jogo 2: https://wordwall.net/play/21399/526/113 (WORDWALL, 2021). Os jogos educativos modelados e analisados nesta pesquisa, proporcionam a aprendizagem 
de aspectos Matemáticos e Estatísticos de uma forma dinâmica, colocando o docente e o aluno em uma interação divertida, ao mesmo tempo que possibilita o lúdico já nas Séries Iniciais do Ensino Fundamental ao abordar conceitos de Probabilidade e Estatística.

O jogo 1 (figura 3 ), foi desenvolvido com o intuito de analisar cenários de aleatoriedade, a fim de apresentar itens baseados na interpretação de dados, utilizando o conhecimento ministrado em aula sobre Estatística e Probabilidade de um fato que pode ou não acontecer. O jogo pedagógico pode ser jogado de maneira individual, ou em grupo em sala de aula.

Figura 3: Jogo 1.

0:09

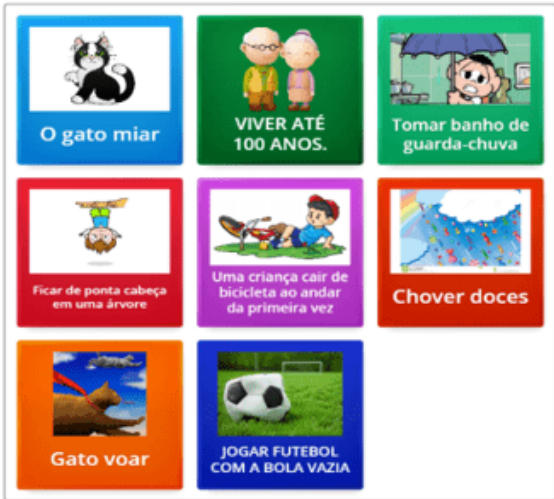

IMPROVÁVEL

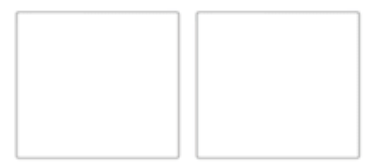

POUCO PROVÁVEL

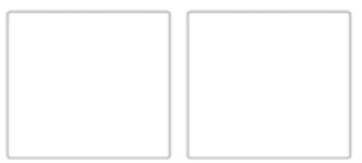

MUITO PROVÁVEL

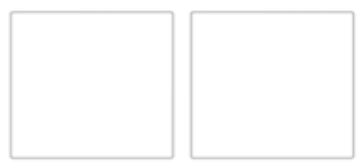

IMPOSSÍVEL

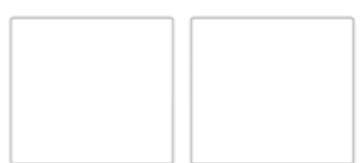

国

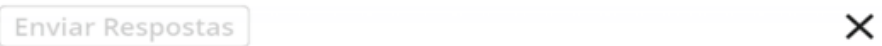

Fonte: $h$ ttps://wordwall.net/play/21400/340/729.

O jogo 2 (Figura 4), foi desenvolvido com o objetivo de o aluno ser capaz de identificar a probabilidade de um evento acontecer. $O$ intuito do jogo é ensinar o estudante a ter noção de aleatoriedade, através das análises de possibilidades de ocorrência em eventos aleatórios e definir quais as chances de ocorrer nas situações mostradas no game. O jogo pode ser ministrado de modo coletivo ou individual, ficando a critério de cada docente.

Devido a facilidade em utilizar a plataforma Wordwall, os professores que utilizam a assinatura básica (gratuita), também possuem a opção de imprimir as atividades, sem 
contar que as atividades são editáveis e podem ser reutilizadas em outras turmas e em diferentes contextos (WORDWALL, 2021). Os jogos didáticos digitais da plataforma Wordwall podem ser criados de forma rápida e prática, não precisa ter conhecimento mais aprofundado de programação, o professor precisa apenas de determinação e curiosidade de pesquisar, pois existem vários tutoriais e canais no YouTube ensinando a trabalhar com a plataforma.

Figura 4: Jogo 2.

\section{Qual a cor mais provável de ser sorteada?}

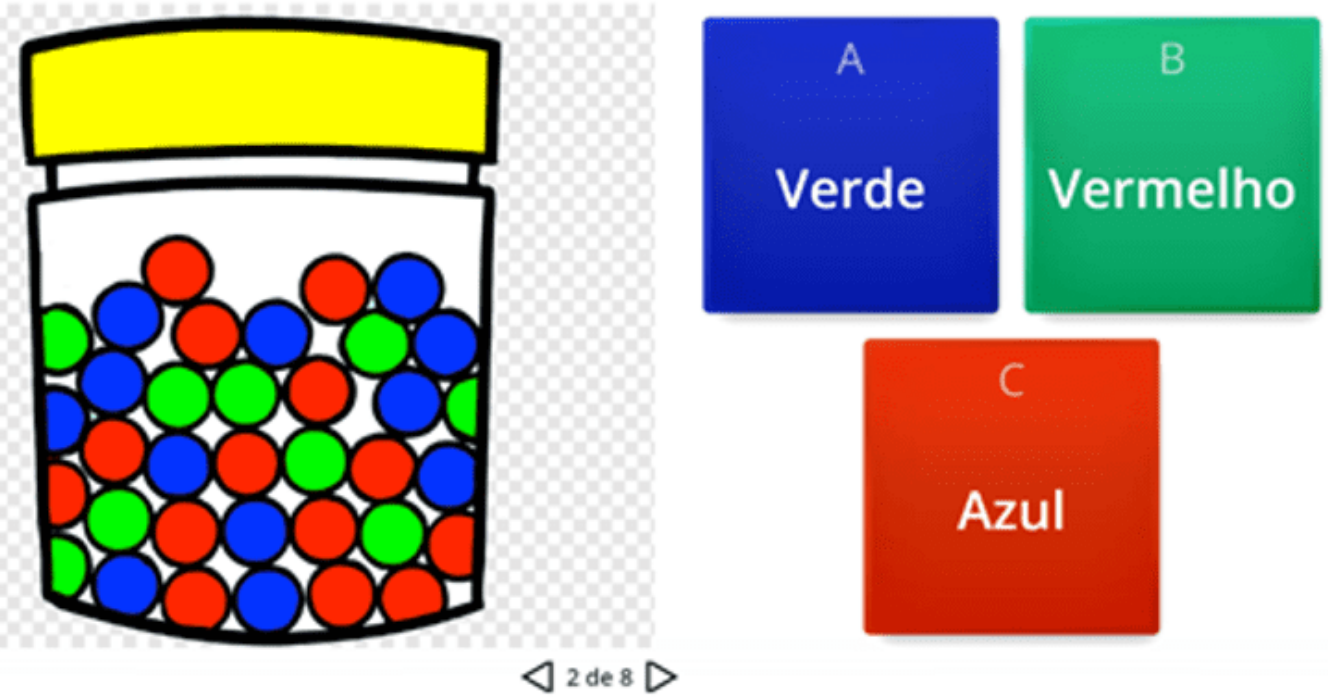

Fonte: https://wordwall.net/play/21399/526/113.

Lemos (2016) demostra a importância da utilização dos jogos digitais como atividades interativas e de aprendizagem no processo de alfabetização de alunos de 6 (seis) à 8(oito) anos de idade do 20 ano do Ensino Fundamental. A autora relata que os jogos digitais podem ser definidos como ambientes atraentes e interativos que capturam a atenção dos jogadores ao oferecer desafios que exigem níveis crescentes de destreza e habilidades.

\subsection{ENTREVISTAS COM OS PROFESSORES}

De acordo com os dados obtidos por meio do questionário aplicado aos professores das series iniciais do Ensino Fundamental da Escola Estadual São Francisco, 
observou-se que $80 \%$ dos docentes entrevistados, possuem alguma dificuldade em trabalhar com ferramentas tecnológicas (Figura 5). A alfabetização digital por parte dos docentes contribui no desenvolvimento social, econômico, cultural e intelectual. A utilização das Tecnologias da Informação e Comunicação (TIC) pelos professores, como recurso no processo de educação e ensino de Estatística, serve como inovação pedagógica principalmente no momento pandêmico que estamos vivendo, mas para que isso ocorra, é fundamental que o educador tenha conhecimento sobre as possibilidades do recurso tecnológico, para utilizá-lo como instrumento de aprendizagem.

Figura 5: Docentes que possuem dificuldades de trabalhar com ferramentas tecnológicas

\section{Professor o senhor possui dificuldades em trabalhar com ferramentas tecnológicas?}

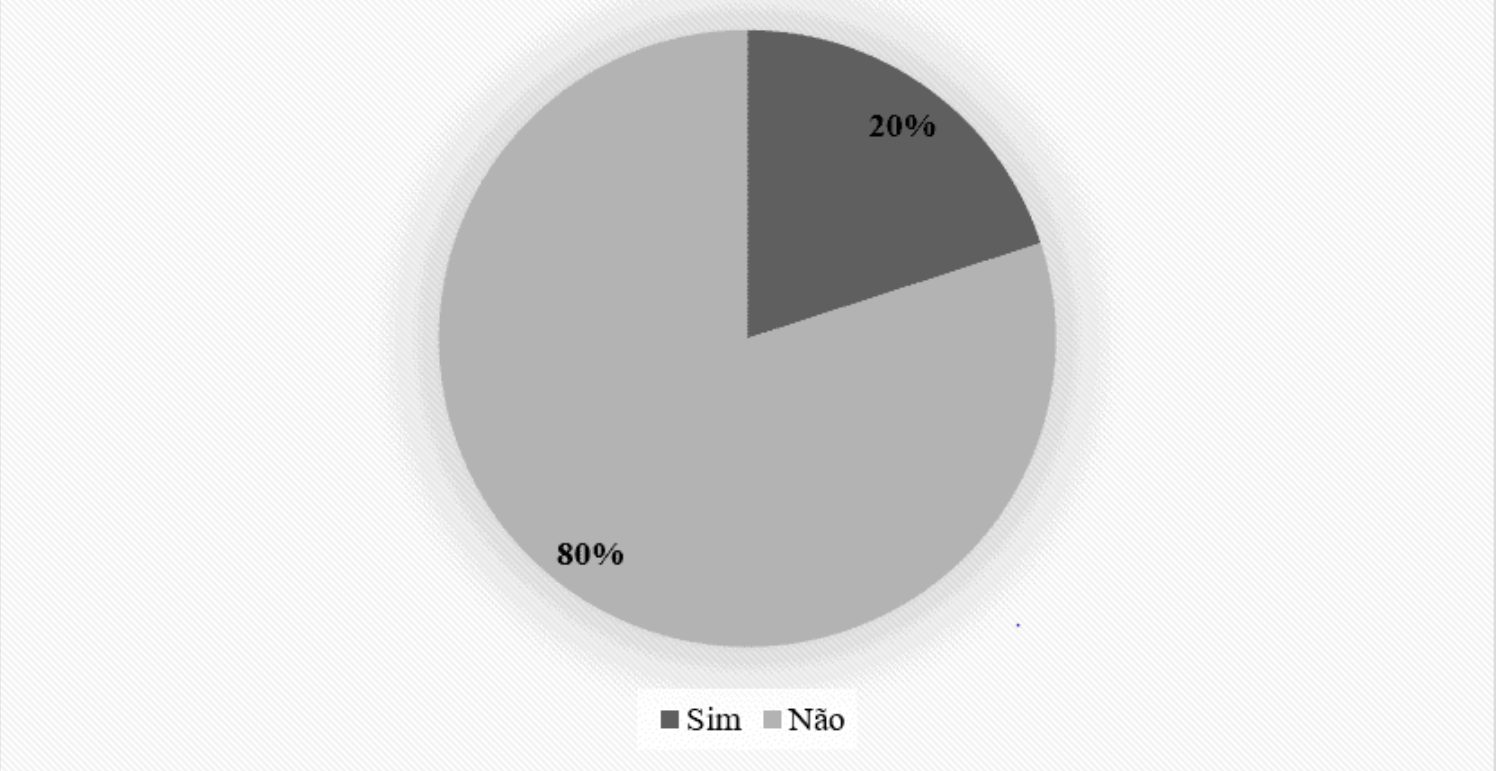

Fonte: Autores (2021).

A formação continuada para professores, nesse contexto de aulas remotas, se constitui num mecanismo para a superação dos desafios educacionais da atualidade, assim como, a necessidade em se manter no mercado de trabalho. Em vista disso, é fundamental o acesso de políticas públicas para a formação inicial e continuada para 
esses educadores. Neste contexto, o papel do docente, passará por um processo de ressignificação, tendo como centralidade o desenvolvimento profissional e cultural do mesmo. Isso somente será possível à medida que o professor buscar capacitação visando a melhoria dos processos de ensino e de aprendizagem, modificando sua prática pedagógica com a integração do uso das novas tecnologias e metodologias de ensino e aprendizagem.

Quando foi perguntado aos professores se os mesmos possuíam alguma dificuldade em ministrar conteúdos de Estatística e Probabilidade nas séries iniciais do Ensino Fundamental. Verificou-se que $80 \%$ dos entrevistados apresentavam dificuldades (Figura 6).

Figura 6: Dificuldades em ensinar Estatística e Probabilidade nas Séries Iniciais

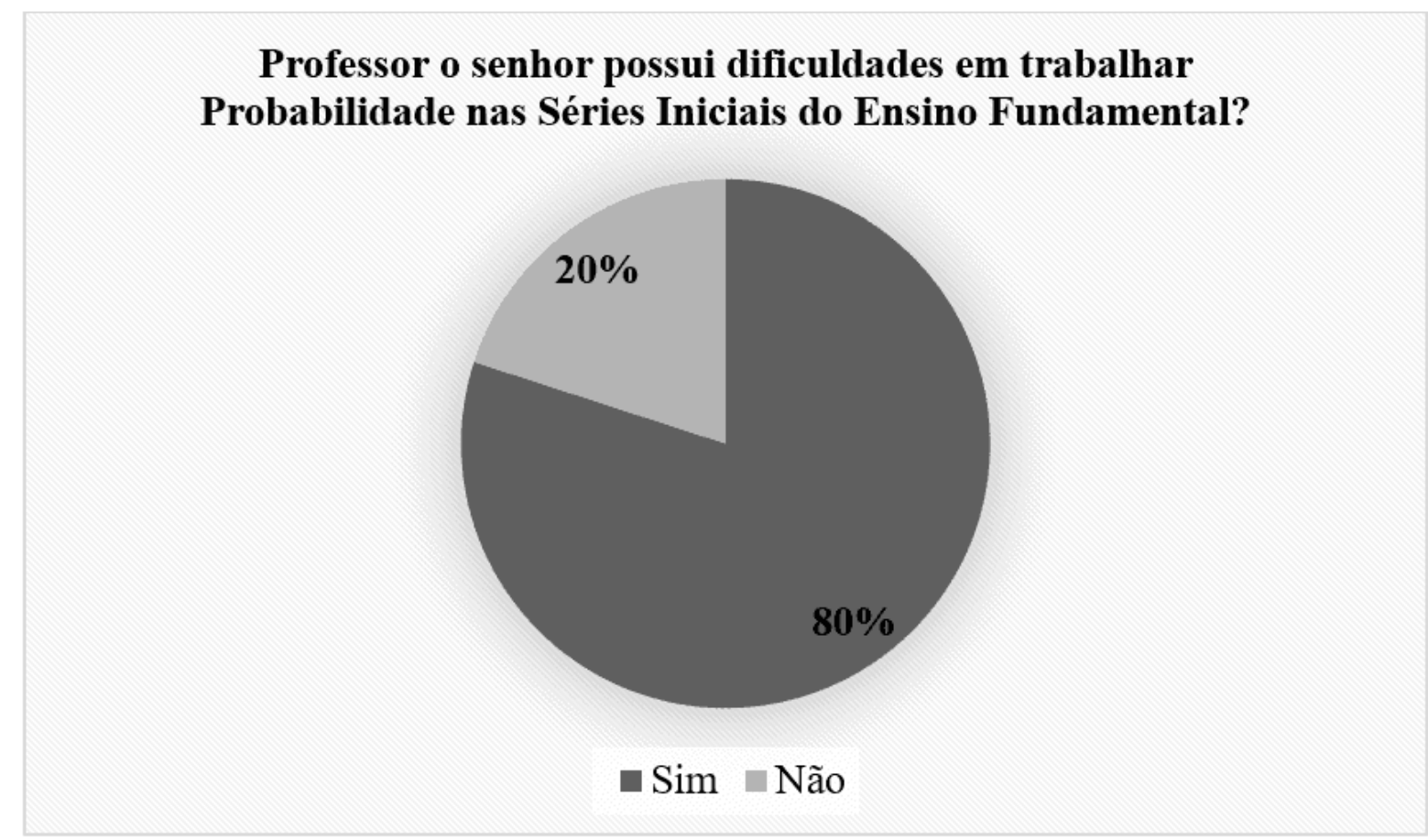

Fonte: Autores (2021).

De acordo com Lima (2011), isso acontece em razão dos professores dos anos iniciais do Ensino Fundamental, em sua maioria, não receberem formação necessária acerca dos conteúdos matemáticos e estatísticos no curso de pedagogia, bem como de estratégias de ensino e avaliação. Um dos principais motivos, se dá pela redução da 
carga horária destinada ao ensino de Matemática nos referidos cursos, e consequentemente, leva à necessidade do docente se tornar mais autônomo em seu aprendizado, buscando permanentemente a formação continuada, visando também se manter no mercado de trabalho.

Com base no questionário observou-se que $40 \%$ dos entrevistados realizavam jogos pedagógicos, número relativamente baixo, comparado aos benefícios de se utilizar essa ferramenta lúdica (Figura 7). Portanto, o ato de brincar ajuda a criança a se estruturar como sujeito da emoção, da razão e da relação. Por essa razão, é tão importante para o aprendizado, pois o aluno é posicionado como o centro do processo de aprendizagem, o professor age apenas como mediador, fazendo com que o ensino seja significativo, e consequentemente tenha a retenção do conteúdo.

Figura 7: Utilização de jogos pedagógicos antes da pandemia de Covid-19

\section{Professor o senhor utilizava jogos pedagógicos antes da pandemia de Covid-19?}

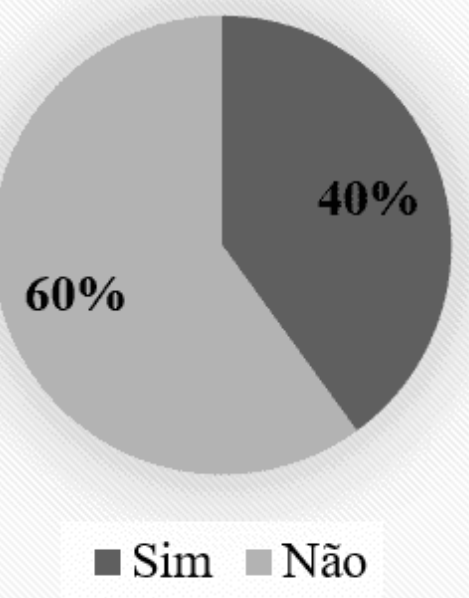

Fonte: Autores (2021).

Mais da metade dos entrevistados confirmaram que irão utilizar jogos pedagógicos após o período de pandemia conforme pode ser observado na figura 8. Entendem a necessidade de utilizar metodologias ativas que coloquem o aluno no centro do processo de aprendizagem. Entretanto cerca de $20 \%$ dos participantes da pesquisa 
relataram que não vão utilizar essa ferramenta de ensino, e os outros $20 \%$ irão utilizar apenas em determinados assuntos, por entender que é importante para o processo de aprendizagem, mesmo que seja necessário realizar formações pedagógicas.

Figura 8: Utilização de jogos pedagógicos depois da pandemia de Covid-19

\section{Professor o senhor irá utilizar jogos pedagógicos após a pandemia de Covid-19?}

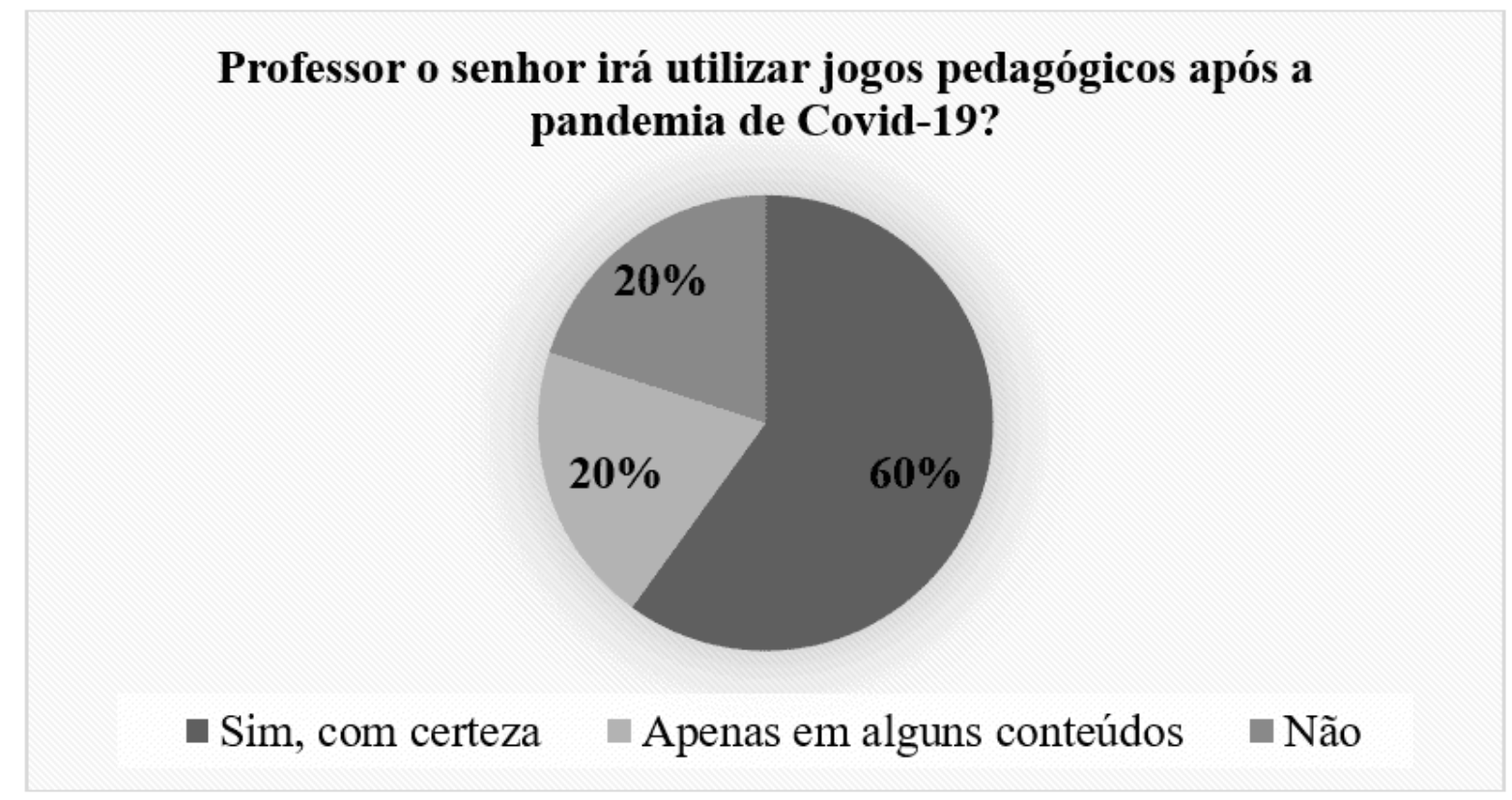

Fonte: Autores (2021).

Entretanto, é importante ressaltar que é preciso mais do que um simples domínio instrumental das ferramentas tecnológicas, torna-se necessário um conhecimento das potencialidades proporcionadas por cada tipo de tecnologia de acordo com cada método de ensino que o professor está utilizando, além do domínio do conteúdo a ser ministrado. O professor precisa ser reflexivo e questionar-se, de que modo esta tecnologia poderá favorecer o seu desempenho como docente em sala de aula e no ensino efetivo da Estatística e da Probabilidade.

Segundo (MORAES e MOTA, 2020) o professor deve conhecer e valorizar os conhecimentos do contexto sociocultural dos alunos, superando a dicotomia entre conhecimento escolar e conhecimento não escolar, visto que a sala de aula é mesclada por uma grande diferença entre os alunos com bagagens culturais 
expressivas e diversas. Os autores ressaltam que é admirável inovar nas práticas pedagógicas, adotando maneiras diferenciadas em sala de aula.

Ao abordar o tema de Tecnologia da Informação na escola Estadual São Francisco, percebeu-se por meio da participação dos professores entrevistados que o uso da ferramenta de criação de jogos e atividades digitais Wordwall ainda é precária, falta formação e estrutura, não era visto como uma metodologia de ensino antes da pandemia de Covid-19, porém, o ensino remoto mostrou a importância e vantagens de se utilizar as ferramentas tecnológicas.

Observou-se que menos de $50 \%$ dos professores possuem formação para o desenvolvimento e aplicação dos jogos digitais, mas consideram o desenvolvimento de jogos como estratégia metodológica para o ensino da Matemática e da Estatística. Existem muitos benefícios ao utilizar jogos interativos virtuais no processo de aprendizagem, vale ressaltar, que a geração atual é conhecida por serem nativos digitais, por isso a utilização de jogos, é uma metodologia assertiva e que possui um bom engajamento, desperta interesse no aluno e the proporciona entretenimento melhorando seu desempenho escolar (LEMOS, 2016; LIMA; SANTARÉM e REBOUÇAS, 2021).

$\mathrm{Na}$ educação escolar o jogo quando trabalhado nas aulas de matemática, passa a ter capacidade de desenvolver potencialidades, habilidades, estímulo de raciocínio e reflexão nos educandos, possibilitando diminuir bloqueios apresentados aos que temem os conteúdos que exigem cálculos (LEMOS, 2016). Os jogos educacionais estimulam o desenvolvimento cognitivo, ajudando na elaboração de estratégias para a solução de problemas, e dá suporte ao professor que tem a oportunidade de ensinar seus alunos de forma lúdica e com diversas ferramentas pedagógicas (LIMA; SANTARÉM e REBOUÇAS, 2021).

Para garantir a eficácia no uso dos jogos educacionais, em que o foco dos games é a aprendizagem, os mesmos precisam ser devidamente planejados com regras bem definidas para atingirem os objetivos didáticos, não se pode deixar os jogadores, jogar de qualquer maneira, as metas e regras precisam ser seguidas com rigor, para que 
os alunos consigam atingir a competência e habilidade do conteúdo estudado. Entretanto, é importante finalizar a aplicação dos games com um feedback sobre o jogo, conteúdos e aplicações de situações cotidianas, deixando os alunos cientes de que o game é importante na sua formação, pois seus ensinamentos como respeito, regras, a tomada de decisões frente aos desafios e problemas matemáticos e estatísticos, devem ser levados para o ambiente escolar, social e profissional. $\mathrm{Na}$ atualidade, o jogo é praticado naturalmente por grande parte das crianças e adolescentes, elas sempre participam em busca de desafios e competição. E uma atividade que estimula a criança a descobrir, observar e interpretar o mundo a sua volta de forma prazerosa (MARINS; COSTA, 2016).

\section{CONSIDERAÇÕES FINAIS}

Diante da problemática levantada, constatou-se por meio da pesquisa, que os professores possuem dificuldades em relação ao ensino remoto e híbrido, bem como a adaptação abrupta da utilização de ferramentas digitais. Os conteúdos da área Probabilidade e Estatística, são considerados difíceis por muitos professores do Ensino Fundamental. O emprego de jogos por meios de plataformas tecnológicas, como a Wordwall, em período de aulas remotas, possibilita aos alunos e professores, uma maneira lúdica de estudar estatística e a maioria dos entrevistados confirmaram que irão utilizar jogos pedagógicos após o período de pandemia.

A apresentação da plataforma online gratuita Wordwall foi de extrema relevância para os professores que trabalham com o ensino da Estatística no componente curricular de Matemática para os anos iniciais do Ensino Fundamental da Escola Estadual São Francisco, localizada no município de Ji-Paraná/RO. Os docentes compreenderam que a utilização desta plataforma pode ser uma aliada, no processo de ensino e aprendizagem de Probabilidade e Estatística, mesmo que seja necessário realizar formações pedagógicas. Os jogos digitais, devem ser incluídos como uma ferramenta de aprendizagem na escola e em casa, pois o século atual está imergido em tecnologia e podemos utilizar isso a favor do processo de ensino. Compreendemos que, é possível ampliar as informações e operações lógicas, a partir dos jogos que os estudantes já conhecem, ou virão a conhecer, e cabe aos educadores participar de 
formação inicial e continuada, para que consigam atingir as expectativas de aprendizagem tanto em casa ou na escola.

\section{REFERÊNCIAS}

BRASIL. Secretaria de Educação Fundamental. Parâmetros curriculares nacionais: matemática \Secretaria de Educação Fundamental - Brasília: MEC \SEF,1998.

BRASIL. Medida provisória no 934, de 1 de abril de 2020. Estabelece normas excepcionais sobre o ano letivo da educação básica e do ensino superior decorrentes das medidas para enfrentamento da situação de emergência de saúde pública de que trata a Lei $\mathrm{n}^{\circ}$ 13.979, de 6 de fevereiro de 2020. Diário Oficial da União, Brasília, DF, 1 abr. 2020. Seção 1, p. 1.

CAMPOS, S. G. V. B.; SANTANA, E. N. Jogos e Brincadeiras para Ensinar e aprender Probabilidades e Estatística nas series iniciais do Ensino Fundamental. In: X ENEM 2010, SALVADOR, 2010.

CAMPOS, C. R.; WODEWOTZKI, M. L. L.; JACOBINI, O.R. Educação Estatística: teoria e prática em ambientes de modelagem matemática. Belo Horizonte: Autêntica Editora, 2011.

FRANCO, M. A. de O.; ZAMPIERI, M. F. de O.; MACIEL, R. G.; CHARLES, R. S. S.; OLIVEIRA L. de. Jogos como ferramenta para favorecer a aprendizagem. In: V Congresso Nacional de Educação. Anais V CONEDU. Campina Grande: Realize Editora p. 1-13, 17 de out. 2018. Disponível em: https://www.editorarealize.com.br/index.php/artigo/visualizar/47704. Acesso em 12 de nov. 2021.

GONÇALVES, C. F. F.; STRAPASSON, E. O Tratamento de Informação: Estatística para o Ensino Fundamental, Londrina: EDUEL, 2007.

GROSSI, M. G. R.; MINODA, D. de S.; FONSECA, R. G. P. Teoria e Prática da Educação, v. 23, n.3, p. 150-170, Setembro/Dezembro 2020. Disponível em: < 
https://periodicos.uem.br/ojs/index.php/TeorPratEduc/article/view/53672>. em: 12 nov. 2021.

IBGE. Instituto Brasileiro de Geografia e Estatística, 2021. Cidades. Disponível em: < https://cidades.ibge.gov.br>. Acesso em: 20 abril 2021.

LEMOS, de F. D. O uso dos jogos digitais como atividades didáticas no $2^{\circ}$ ano do Ensino Fundamental. 2016, 26 f. Monografia (Especialista em Educação na Cultura Digital). Universidade Federal de Santa Catarina - UFSC, 2016.

LIMA, N. de O. Educação matemática: uma possibilidade de inovação pedagógica. 2020. 134 f. Dissertação (Mestrado em Ciência da Educação). Faculdade de Ciências Sociais da Universidade da Madeira -FUNCHAL, 2020.

LIMA, S. M. A formação do pedagogo e o ensino da matemática nos anos iniciais do ensino fundamental. 2011. 212 f. Dissertação (Mestrado em Educação). Universidade Federal de Mato Grosso/UFMT, Cuiabá, 2011.

LIMA, T. P. de O.; SANTARÉM, L. C. A.; REBOUÇAS, O. B. O uso de jogo digital educacional como instrumento didático no processo de ensino-aprendizagem da língua portuguesa e matemática, Brazilian Journal of Development, v.7, n.3, p. 24517-24530, 2021.

MARSHALL, L.; PAUL, S. Exploring the Use of Mathematics Manipulative Materials: Is It What We Think It Is? In: International Conference. Sustainability in Higher Education: Directions for Change, Edith Cowan University, Perth Western Australia, p. 338-350, 19 - 21 de novembro de 2008. Disponível em: https://ro.ecu.edu.au/cgi/viewcontent.cgi?article=1032\&context=ceducom. Acesso em: 01 fev. 2021.

MARINS, D. S. de; COSTA, C. R. B. Recreação Escolar: o brinquedo a brincadeira e o jogo na educação da infância. Revista Científica Multidisciplinar Núcleo do Conhecimento, Ano 1, v 10, p. 05- 24. 2016. Disponível 
em: https://www.nucleodoconhecimento.com.br/educacao/recreacao-escolar Acesso em: 20 nov. 2021.

MORAES, F. B. P. de. MOTA, V. C. Confecções de roupas: Um olhar etnomatemático. Revista Científica Multidisciplinar Núcleo do Conhecimento. Ano 05, Ed. 10, v. 06, p. 42-61. Outubro de 2020. ISSN: 2448-0959, Disponível em: https://www.nucleodoconhecimento.com.br/matematica/confeccoes-de-roupas. Acesso em: 23 abr. 2021.

MOTA, V. C.; GOMES, J. C.; SANTOS, A. M. dos; BeniteZ, V. M. S. Ensinando gráficos na escola indígena: uma possibilidade de diálogos interculturais, In: Actas del VII CIBEM ISSN, v. 2301, n. 0797, p. 7873-7873, 2013.

MUNIZ, C. A. Brincar e Jogar: e lances teóricos e metodológicos o campo da educação matemática. Belo horizonte: Autentica, 2010.

ORGANIZAÇÃO MUNDIAL DA SAÚDE - OMS. Histórico da pandemia de COVID19. Folha informativa sobre COVID-19. Geneva: WHO, 2020. Disponível em: https://www.paho.org/pt/covid19/historico-da-pandemia-covid-19. Acesso em: 12 maio. 2021

PEREIRA, C. S.; DIAS, C. de F. B.; JUNIOR, G. dos S. Materiais Didáticos para o Ensino de Estatística: uma análise a partir de relatos de experiências do XII ENEM. Ciências Humanas. Revista Thema, v. 15, n. 3, p. 1007-1015, 2018. Disponível em: https://www.researchgate.net/publication/327026307_Materiais_Didaticos_para_o_E nsino_de_Estatistica_uma_analise_a_partir_de_Relatos_de_Experiencia_do_XII_E NEM. Acesso em: 03 abr. 2021.

SANTANA, W. F. A importância dos jogos didáticos virtuais para o ensino e aprendizagem de matemática. 2021. 25 f. Trabalho de Conclusão de Curso (Graduação Especialização em Ensino de Ciências Matemáticas) - Instituto Federal Goiano, campus Campos Belos, 2021. 
SANTOS, A. N. A. dos. Ludicidade e Infância: A Importância do lúdico no aprendizado da criança. 2011. 71 f. Trabalho de Conclusão de Curso (Graduação em Pedagogia) - Universidade Estadual de Londrina, Londrina, 2011.

SILVA, T. de O.; SILVA, L. T. G. Os impactos sociais, cognitivos e afetivos sobre a geração de adolescentes conectados às tecnologias digitais. Rev. Psicopedag. São Paulo, v. $\quad 34$, n. $\quad 103$, p. 87-97, $2017 . \quad$ Disponível em <http://pepsic.bvsalud.org/scielo.php?script=sci_arttext\&pid=S0103$84862017000100009 \&$ lng=pt\&nrm=iso $>$. Acesso em 28 set. 2021.

SOUSA, D. B. de. O ensino e aprendizagem através dos jogos e brincadeiras. In: III CONEDU, Congresso Nacional de Educação. 2016.

VYGOTSKY, L. S. A formação social da mente: o desenvolvimento dos processos psicológicos superiores. 2. ed. São Paulo: Martins Fontes, 1991.

WORDWALL. Atividades interativas e imprimíveis. 2021. Disponível em: https://wordwall.net/pt. Acesso em 17 de jul. 2021.

Enviado: Outubro, 2021.

Aprovado: Dezembro, 2021. 